\title{
A INSTITUCIONALIZAÇÃO DO ENSINO DE ARQUITETURA PAISAGÍSTICA NO RIO DE JANEIRO
}

\author{
LANDSCAPE ARCHITECTURE EDUCATION INSTITUTIONALIZATION IN RIO DE JANEIRO
}

\author{
Alda de Azevedo Ferreira* \\ Fernando Pedro de Carvalho Ono** \\ Cláudia Carvalho Leme Nóbrega***
}

\section{RESUMO}

O ensino de arquitetura paisagística foi instituído pela primeira vez no Rio de Janeiro na década de 1930. Iniciado na Escola Nacional de Belas Artes a partir de reforma promovida por Lucio Costa entre os anos 1930 e 1931 a disciplina foi introduzida junto com a de urbanismo, originando a cátedra 'Urbanismo e Arquitetura Paisagística'. Este artigo objetivou entender esse processo a partir de informações colhidas em fontes primárias, fundamentado pelos conceitos de campo e habitus, de Pierre Bourdieu. Descobriu-se que o arquiteto e urbanista Attílio Corrêa Lima foi o primeiro professor da disciplina e que o ato da inclusão disciplinar estava inserido na construção de um campo paisagístico na cidade do Rio de Janeiro naquele momento, propagado não só no campo da arquitetura, como articulado às esferas política, econômica, e social. Palavras-chave: Arquitetura paisagística. Ensino superior. ENBA. Attílio Corrêa Lima.

\section{ABSTRACT}

Landscape Architecture education was first established in Rio de Janeiro, in the 1930s. Introduced in Escola Nacional de Belas Artes (National School of Fine Arts), based on the reform promoted by Lucio Costa between 1930 and 1931, the program was included along with Urban Design, originating the 'Urban Design and Landscape Architecture' chair. This article aims at understanding this process, using information collected from primary sources, based on Pierre Bourdieu's concepts of field and habitus. Architect and urban designer Attílio Corrêa Lima was the first professor to teach this program, and the act of placing the program within a Landscape Architecture field helped make room for these studies in the city of Rio de Janeiro, which spread not only to the Architecture field, but also reached the political, economic, and social spheres.

Keywords: Landscape Architecture. Higher Education. ENBA. Attílio Corrêa Lima.

\footnotetext{
* Universidade Federal do Rio de Janeiro, Programa de Pós-Graduação em Arquitetura. Av. Pedro Calmon, 550, Cidade Universitária, CEP 21941-485, Rio de Janeiro, RJ, Brasil. CV: http://lattes.cnpq.br/5499509018406897 aldazevedo@yahoo.com.br

** Universidade Federal do Rio de Janeiro, Programa de Pós-Graduação em Artes Visuais da Escola de Belas Artes. Av. Pedro Calmon, 550, Cidade Universitária, CEP 21941-485, Rio de Janeiro, RJ, Brasil. CV: http://lattes.cnpq.br/1772813852619682 fono_6@yahoo.com.br

*** Universidade Federal do Rio de Janeiro, Programa de Pós-Graduação em Arquitetura. Av. Pedro Calmon, 550, Cidade Universitária, CEP 21941-485, Rio de Janeiro, RJ, Brasil. CV: http://lattes.cnpq.br/1692022058894495 claudiaclnobrega@gmail.com
} 


\section{INTRODUÇÃO}

O período de 1930 a 1965 caracteriza-se por ser uma época de transição na organização social brasileira. De acordo com Abreu (2013), tal fato é decorrente do caráter contraditório da Revolução de 1930, que teve como objetivo desalojar do poder a aristocracia cafeeira, mas que contraditoriamente, não possuía nenhum outro grupo solidamente organizado para substituí-la. A Revolução, ocorrida na década de 1930 (século XX), foi organizada por uma variedade de classes e camadas sociais, obrigando o governo a alternar períodos de favorecimento de uma classe ou grupo com épocas em que privilegiava demandas de outros setores sociais.

Tem início assim o governo do presidente Getúlio Vargas, período em que governou o país por 15 anos ininterruptos, entre 1930 e 1945. O evento de instância decisiva na fase inicial do governo é a elaboração de medidas de caráter nacional - inclusive as de educação - por meio do controle e mecanismos autoritários e repressivos. Buscava-se forjar a ideia de 'nação brasileira', amparada pela noção europeia de civilização. Uma questão que se impôs de forma crescente foi a busca de uma identidade nacional, gerando a discussão que se estendeu ao campo da arquitetura, da literatura e das artes e que produziu a histórica Semana de Arte Moderna em 1922 (AMARAL, 1998).

O governo, então, elabora seu projeto universitário durante a década de 1930, período que ficou conhecido como "Reforma Francisco Campos". Cria-se, inicialmente, - Ministério da Educação em 1930, e são adotadas diversas medidas, entre as quais se destacam a promulgação do Estatuto das Universidades Brasileiras (Decreto-Lei $n^{\circ}$ 19.851/31), a reorganização da Universidade do Rio de Janeiro (Decreto-Lei $n^{\circ}$ 19.852/31) e a criação do Conselho Nacional de Educação (Decreto-Lei nº 19.850/31). Posteriormente, é desenvolvida a proposta de reestruturação do Ministério da Educação e Saúde Pública, em 1935, e da institucionalização da Universidade do Brasil, em 1937, como modelo padrão para as demais universidades existentes no país (ROTHEN, 2008).

Esses anos, que se iniciavam arrastados pela crise econômica de 1929, viram acentuar-se no país a penetração das linhas ideológicas de direita e esquerda e foram férteis na procura da afirmação de novas dimensões culturais, ainda como reflexo do movimento modernista na Semana de 1922. Mesmo com a Revolução de 1930, havia a presença de homens favoráveis à problemática contemporânea da arte no então Ministério da Educação e Saúde, o que iria se revelar como uma brecha no sistema, com importantes consequências para a consolidação daquelas ideias (ZANINI, 1983).

Tal ambiente assinalou o crescente número de adeptos do Modernismo, onde a arte surge como resposta ao espírito moderno que pregava a ruptura com antigos valores, traduzida pela liberdade da criatividade dos artistas, que transformavam a realidade no foco de suas produções. Uma das propostas desse momento era construir o caráter nacional da produção artística, rompendo com as influências estrangeiras e democratizando-o para todas as classes sociais. Paralelamente, instalava-se no país o projeto de modernização fomentado pelo estado, incentivando as reformas das cidades, como descreve Pereira (2008). 
Nesse contexto, a cidade do Rio de Janeiro ocupava posição de destaque nacional como capital da República do Brasil, e o paisagismo até então nela praticado era caracterizado pelo forte formalismo dos planos de 'embelezamento'. Todavia, a partir da década de 1930, ocorre uma ruptura nessa prática, passando a ganhar vigor uma expressão mais diretamente vinculada aos estímulos autóctones do meio, e com isso emergem os primeiros paisagistas modernistas cariocas. É nesse cenário que ocorre a institucionalização do ensino de arquitetura paisagística na cidade.

Contudo, até hoje poucos estudos se dedicaram a abordar tal empreendimento sob o ponto de vista da sua articulação com as transformações contextuais que estruturaram a introdução disciplinar. Assim, objetiva-se neste artigo promover uma reflexão sobre esse processo, abarcando essa primeira iniciativa. A pesquisa foi baseada em fontes primárias de periódicos da época, e amparou-se nos conceitos de campo e habitus, oriundos dos fundamentos de Bourdieu (2011), adotado como suporte para melhor entendimento dessas modificações.

\section{OS CONCEITOS DE CAMPO E HABITUS}

O filósofo e sociólogo Pierre Bourdieu desenvolveu um método para análise do espaço social baseado na relação entre as posições sociais (conceito relacional), as disposições (ou o habitus) e as tomadas de posição, ou as escolhas que os agentes sociais fazem nos domínios mais diferentes da prática, onde a comparação só é possível entre sistemas, observando-se suas distinções (separação, traço distintivo) - propriedade relacional que só existe em relação a outras propriedades. Por meio dessa visão, o sujeito e suas ações não podem ser descritos como fenômenos exclusivamente internos, nem tampouco como simples reflexo de seu meio social.

Tal pensamento deriva do princípio que compreende a dinâmica social como algo que se dá no interior de um campo, um segmento social cujos agentes - indivíduos e grupos - têm disposições específicas, denominadas por Bourdieu de habitus. Este conceito foi retomado por Bourdieu (2011, p. 21-22) e diz respeito aos gostos, aos modos de vida da sociedade e tradições que lhes são distintivas: "[...] o habitus é esse princípio gerador e unificador que retraduz as características intrínsecas e relacionais de uma posição em um estilo de vida unívoco, isto é, em um conjunto unívoco de escolhas, de pessoas, de bens, de práticas".

Por sua vez, campo, segundo Bourdieu (2011), é compreendido não como um lugar específico, mas como uma situação atual de um assunto numa justaposição de sua materialidade e sociabilidade. Em seu conceito de campo, considera a lógica interna dos objetos culturais, sua estrutura como linguagens e os grupos que produzem tais objetos, através dos quais também preenchem funções. Para tanto é necessário utilizar o método relacional para análise do microcosmo social no qual se produzem obras culturais, como o campo artístico no qual se insere o paisagismo. Segundo Bourdieu: 
É isso que acredito expressar quando descrevo o espaço social global como um campo, isto é, ao mesmo tempo, como um campo de forças, cuja necessidade se impõe aos agentes que nele se encontram envolvidos, e como um campo de lutas, no interior do qual os agentes se enfrentam, com meios e fins diferenciados conforme sua posição na estrutura do campo de forças, contribuindo assim para a conservação ou transformação da estrutura (BOURDIEU, 2011, p. 50).

Tais fundamentos teórico-metodológicos se prestam à análise dos mecanismos de dominação, produção de ideias e gênese das condutas. Busca-se, por meio deles, o desvelamento da articulação do social que levou à institucionalização da disciplina de arquitetura paisagística na então Escola Nacional de Belas Artes (ENBA) no início da década de1930.

\section{A INTRODUÇÃO DA ARQUITETURA PAISAGÍSTICA NO ENSINO DA ESCOLA NACIONAL DE BELAS ARTES}

A Escola Nacional de Belas Artes (ENBA) era herdeira inicialmente da Escola Real de Ciências Artes e Ofícios (1816-1822), fundada por D. João VI no século XIX por incentivo da Missão Artística Francesa. Estruturada no sistema acadêmico, inaugurou o ensino artístico no país nos moldes formais, apoiada nos preceitos do Classicismo, conforme descreve Pereira (2008). Após a Independência do Brasil, a instituição passou a ser conhecida como Academia Imperial de Belas Artes - AIBA (1822-1890).

A ENBA foi criada em 8 de novembro de 1890, nascendo com o regime republicano. Teve como objetivo romper com o modelo imperial de ensino e de gosto artístico, porém não é possível perceber de início grandes rupturas entre as duas instituições. A partir de 1931, foi integrada à então denominada "Universidade do Rio de Janeiro", criada em 7 de setembro de 1920 pelo presidente Epitácio Pessoa por meio do Decreto $n^{\circ} 14.343 / 20$, delimitando o fim de um sistema e o início de outro.

A Universidade do Rio de Janeiro, por sua vez, era descendente direta dos primeiros cursos de ensino superior do Brasil, e resultante da justaposição inicial de três escolas tradicionais - Escola Politécnica, Faculdade Nacional de Medicina e Faculdade Nacional de Direito - às quais outras se somaram, como a Escola Nacional de Belas Artes e a Faculdade Nacional de Filosofia. Com isso, a Universidade do Rio de Janeiro representou papel fundamental na implantação do ensino de nível superior no país. A tradição de seus cursos pioneiros deu-lhe o papel de celeiro dos professores que implantaram os demais cursos de nível superior no Brasil.

Foi na ENBA que se deu a introdução da disciplina de paisagismo no currículo de seu Curso Geral, ocorrida através da reforma promovida pelo arquiteto Lucio Costa quando assumiu a direção no período de 1930 a 1931. Nesse momento a instituição se localizava no prédio que atualmente abriga o Museu Nacional de Belas Artes, situado na antiga avenida Central - atual avenida Rio Branco - no centro da cidade do Rio de Janeiro. Lucio Costa, segundo a ata da Sessão da Congregação da Escola Nacional 
de Belas Artes, realizada em 22 de abril de 1931, assumiu sua direção almejando introduzir elevação e eficiência ao Curso Geral, na época dividido entre três anos de disciplinas do curso de arquitetura e três anos de pintura e matérias correlatas.

A presença de Lucio Costa à frente da ENBA, segundo Walter Zanini (1983), deveu-se à indicação de Rodrigo Mello Franco de Andrade, chefe do gabinete do então Ministro da Educação, Francisco Campos, na presidência de Washington Luís. Assim, o jovem arquiteto Lucio Costa, com 29 anos incompletos, e que paulatinamente vinha adotando a linha funcionalista de Le Corbusier, assumiu a direção da instituição academicista. Pinheiro (2005) ressalva que o convite é anterior à Revolução de 1930, como foi registrado na primeira reunião da Congregação da Escola, na qual consta a assinatura de Lucio Costa como diretor na data de 13/9/1930. Após a Revolução, Francisco Campos permanece no Ministério, de modo que a data do início do mandato de Costa é oficialmente 8/12/1930.

A nomeação de Lucio Costa, conforme Pinheiro (2005), estava inserida numa questão mais abrangente, na base do Ministério da Educação do governo revolucionário, que consistia na reforma universitária. Tratou-se, portanto, de um processo geral de normatização e regularização das instituições de ensino superior, e não de uma reforma pontual. O processo culminou com a promulgação do Decreto $n^{\circ} 19.851$ de 11 de Abril de 1931, que consistiu no Estatuto das Universidades Brasileiras, dando origem a uma estrutura institucional baseada em órgãos colegiados, como o Conselho Universitário e os Conselhos Técnicos e Administrativos.

Neste ínterim Costa instituiu uma reforma curricular imputando ao Curso Geral caráter moderno através do incentivo ao regime pedagógico, com largo desenvolvimento do ensino técnico-científico por meio da introdução das disciplinas de urbanismo, arquitetura paisagista, composição decorativa e tecnologia das artes menores e a obrigatoriedade dos trabalhos práticos. Para tanto contratou novos professores por seu livre arbítrio, mas ao mesmo tempo em que renovava, mantinha velhos mestres, obedecendo assim a um espírito de conciliação. Foram então contratados: o arquiteto Gregori Warchavchik para a cadeira de Composição de Arquitetura do $4^{\circ}$ ano, o escultor Celso Antônio para a de Escultura, o arquiteto alemão Alexander Buddeus para a de Composição de Arquitetura do $5^{\circ}$ ano e o pintor alemão Leo Putz para uma das cadeiras de Pintura (PINHEIRO, 2005).

Contudo, a falta de registros acerca da recém-criada cadeira de 'urbanismo e arquitetura paisagista' leva a compreender que durante a direção de Lucio Costa na ENBA ela não foi ocupada. De toda forma, vale destacar que sua atitude de reconhecer a disciplina do paisagismo não foi ao acaso e tampouco fruto exclusivo de sua subjetividade. Sua posição social estava inserida num campo mais amplo, em articulação à esfera político-intelectual do momento.

Conforme o sociólogo francês e especialista em problemas políticos da América Latina, Daniel Pécaut (1990), a politização dos intelectuais brasileiros da primeira geração, definida entre 1920-1940, reclamava para si próprios a autoridade perante o estado para executar sua missão política, basicamente definida por duas tarefas: forjar 
a 'consciência nacional' e promover a 'organização social'. $O$ acesso dos intelectuais à posição de elite dirigente qualificava-se por sua capacidade em captar e interpretar os sinais que demonstravam a existência de uma nação inscrita na realidade. $E$, no que tange à arquitetura paisagística, tais sinais se davam pelos mais diversos campos.

Em arquitetura lutava-se desde 1929 pela regulamentação da profissão de arquiteto e pela diferenciação de suas atribuições em relação às dos engenheiros. $\bigcirc$ Instituto Central de Arquitetos, nesse momento, era presidido por Adolfo Morales de Los Rios Filho, arquiteto e professor da ENBA, tendo como vice-presidente Cipriano Lemos. Em seu discurso de posse em 1929, Morales de Los Rios Filho chama atenção para essa urgente necessidade, informando que o Ministro da Justiça havia solicitado ao Conselho Superior de Ensino a elaboração de um anteprojeto regulamentando a profissão de engenheiro, que serviria de base para o Projeto de Lei a ser enviado para a Câmara. Assim era de suma importância definir atribuições, direitos e deveres dos arquitetos distintos em relação a engenheiros e construtores. Em suas palavras era pertinente ao arquiteto o trabalho paisagístico com a função de higienizar as cidades e educar a sociedade:

Homem de arte e de sciencia, homem de acção e de sociedade, psychologo, historiador, mestre de obreiros, conductor de correntes estheticas, planejador e reformador de cidades, parques e jardins, domador e estheta da natureza, educador e hygienista, eis definida a personalidade do architecto (LOS RIOS FILHO, 1929, p. 22-23).

De 19 a 30 de junho de 1930 foi realizado na cidade do Rio de Janeiro o IV Congresso Pan-Americano de Arquitetos, que contou inclusive com a participação de Lucio Costa. Conforme matéria de Adolfo Morales de Los Rios Filho para a "Revista de Architectura" (9/1929), entre os objetivos do Congresso estava pugnar os melhores conhecimentos dos problemas artísticos, científicos, urbanísticos, paisagísticos, técnicos e sociais, e entre os eixos teóricos abordados havia um que versava sobre os problemas relacionados ao "urbanismo e architectura paysagista". Segundo matéria do Jornal do Brasil (2/7/1930), o Congresso causou grande impacto no meio dos arquitetos e repercutiu internacionalmente em todo o continente americano. Entre as recomendações resultantes das discussões, destaca-se: "O Congresso recomenda a creação de cadeiras ou mesmo cursos de urbanismo nas escolas superiores de architectura e engenharia, devendo haver, egualmente, ao menos nas primeiras, o ensino especializado do paisagismo (grifo nosso).". (JORNAL do Brasil, 2/7/1930, p. 8).

Houve ainda um movimento iniciado pela Sociedade Brasileira de Belas Artes, em prol da arquitetura paisagística, por meio do qual se planejava iniciar exposições anuais que contribuíssem para a sistematização didática dessa especialidade. Fazia parte de um movimento ainda maior, que visava à conservação florística do Rio de Janeiro. Segundo matéria escrita por Sampaio para o jornal Correio da Manhã (19/1/1930), intitulada "A flora do Rio de Janeiro", a floresta deveria ser considerada pelos cariocas como algo a conservar onde permanecesse e a recompor onde necessário. Sampaio 
cita as palavras do arquiteto José Mariano Filho, que dizia ser o Rio de Janeiro uma "cidade-floresta" e, portanto, necessitavam serem conservados os "[...] dons particulares que a natureza benfazeja reservou para cada região, no dizer de Humboldt" (SAMPAIO, 1930, p. 3).

Até mesmo nas bases do programa do Partido Economista do Brasil, lançado em 1931, de acordo com matéria do Diario da Noite (12/11/1932) propõe-se criar o ensino de arquitetura paisagística nos cursos de arquitetura e de agronomia. Em outras palavras, havia um ambiente propício onde era reconhecida a importância da arquitetura paisagística para a constituição da cidade e da qualidade de vida das pessoas. Tal ambiente tinha conexão com o cenário político-intelectual da época, caracterizado por preocupações nacionalistas e cientificistas, aliado ao desejo de modernização da sociedade e das instituições e estado.

Tratava-se, portanto, da construção coletiva de um campo paisagístico na cidade do Rio de Janeiro como reflexo de um grupo mobilizado para e pela defesa de seus interesses, buscando sua própria estrutura e suas próprias leis. Nesse grupo estavam inseridos o poder político e os intelectuais que almejavam a construção do Estado Nacional forte e de uma identidade pátria, cuja iniciativa passava também pela conservação do meio ambiente e pelo seu reconhecimento como patrimônio natural e signo identitário da nação, de modo que sua inclusão nas cidades através do tratamento paisagístico estava contida nesses objetivos.

Ressalta-se também a importância do caráter histórico do conhecimento: a história do paisagismo no espaço público da cidade do Rio de Janeiro tem sua gênese no período colonial, com a criação do Passeio Público (1779). Desse momento em diante diferentes práticas se estabeleceram na cidade, contribuindo para a construção cotidiana de saberes paisagísticos. Tal fato é bastante relevante, pois a historicidade na construção do conhecimento se constitui como forma de questionar a objetividade dos saberes, considerando que estes são configurados na história da sua produção.

\section{A CONSTRUÇÃO DO HABITUS PAISAGÍSTICO CARIOCA}

O então nomeado Passeio Público da Corte, criado por obra de Valentim da Fonseca e Silva no século XVIII, era uma grande mistura de referências - entre o barroco brasileiro, o neoclássico e o romântico - que leva a crer que no final das contas não era nem uma coisa nem outra, e sim a proeminência de um modo de ver próprio da paisagem carioca. $\bigcirc$ paisagismo carioca emergente nesse momento, que se pretendia 'ilustrado', em verdade relacionava-se com a forma que se estava vivendo, aliado às características do meio ambiente.

A primeira institucionalização da prática paisagística na cidade do Rio de Janeiro deu-se em 18 de abril de 1839, através da nomeação do naturalista alemão Ludwig Riedel para a direção do então Jardim Botânico do Passeio Público, assumindo o cargo de 'jardineiro botânico'. Em sua prática o Passeio Público passava a caracterizar-se por ser não apenas um espaço de sociabilidade como jardim de passeio, mas tam- 
bém afirmar sua vocação como horto botânico, onde eram realizados estudos com a flora nativa e exótica.

Após o falecimento de Riedel, em 1861, o francês Auguste François-Marie Glaziou assumiu a direção e conservação do Passeio Público na função de 'diretor botânico'. Em 26 de janeiro de 1869, foi nomeado Diretor de Parques e Jardins da Casa Imperial, dando continuidade à prática instituída inicialmente por Riedel. Posteriormente assumiu também o cargo de Inspetor de Jardins Municipais. Porém, ressalta-se que na prática de Glaziou na cidade do Rio de Janeiro, marcada inicialmente pela reforma do Passeio Público, a imanência dos saberes construídos ao longo de quase meio século é por ele conservada, à qual são acrescentados outros, próprios do período em que vivia. Seus conhecimentos de botânica estimularam a busca pela flora nativa em expedições realizadas com o intuito de identificar novas espécies.

A cidade do Rio de Janeiro apresentava uma realidade bem contrastante em meados do século XIX. Marcada pelo desmatamento e o reaproveitamento de terras, e drenagens com a finalidade de 'expulsar' os miasmas exalados das lagoas e mangues, frequentes em seu território, a cidade já começava a surtir os efeitos provocados pelo desmatamento da floresta da Tijuca para o plantio do café, especialmente no abastecimento de água.

Tal contexto favoreceria, como subproduto, uma mudança de gosto caracterizada pela apreciação do meio ambiente 'intacto', pela terra inculta, pelo gosto do 'pitoresco', aos moldes do que a cultura inglesa vinha apresentando desde fins do século XVIII. As viagens pitorescas, bem como os poemas, diários, pinturas e gravuras topográficas que as promoviam e celebravam, originavam-se de lucros provenientes da agricultura melhorada e do comércio. Nesse nível, não se trata de mudança de sensibilidade, estritamente falando, e sim de uma aquisição de gosto. Assim, aos poucos, ao longo do século os moradores foram estabelecendo jardins em suas casas localizadas nos arrabaldes da cidade.

O gosto por jardins contribuiu inclusive para impulsionar o desenvolvimento da prática informal da jardinagem doméstica através do incentivo à vinda de mão-de- obra imigrante e o desenvolvimento da instrução agrícola. A prática cresceu em progressão diretamente proporcional à expansão urbana e o crescimento da população, visivelmente compreendida através do aumento da oferta de serviços profissionais.

Foram então construídos muitos jardins na cidade carioca e várias praças foram ajardinadas. Alçado pela elite e legitimado pelo suporte de uma política pública sistemática da Câmara Municipal, em comunhão com o poder imperial, gradativamente distingue-se esse gosto na cidade do Rio de Janeiro, fundamentado nos enunciados de 'salubridade' e 'aformoseamento'.

Nos primórdios do século XX tem-se o primeiro profissional a adotar formalmente a alcunha de 'architecto paysagista' na cidade carioca: o francês Paul Villon. Ele havia substituído Auguste François-Marie Glaziou, em 1900, na Inspectoria de Mattas Terrestres e Marítimas, Caça e Pesca do Rio de Janeiro (órgão criado após a proclamação da República), na função de jardineiro-chefe. Em 1902 a instituição 
uniu-se a outro órgão público, a Inspectoria de Mattas Marítimas e Pescas, e passou a chamar-se Inspectoria de Mattas, Jardins, Arborisação, Caça e Pesca. Segundo matéria do Jornal do Brasil (23/08/1902), no Artigo $3^{\circ}$ do regimento da Inspetoria, o cargo de jardineiro-chefe foi substituído pelo de 'architecto paysagista'.

Em observação à prática executada por Villon na Inspetoria, todavia, não se notam especificidades que o distingam do paisagista de meados do século XIX. Ao contrário, nessa época Glaziou havia se autodenominado 'horticultor-paisagista', e no cargo por ele ocupado se dedicou profundamente às pesquisas sobre a flora nativa. Nesse sentido, percebe-se a ausência de saberes botânicos na prática de Paul Villon, que deu mais ênfase à questão artística na concepção de seus jardins por meio de planos de embelezamento.

Até a década de 1920, no Rio de Janeiro a arquitetura paisagista estava fortemente imbricada à prática da agricultura, estando relacionada ao campo da agronomia e da botânica. Tratava-se de uma prática associada ao pensamento de embelezamento/ aformoseamento das cidades, difundida pelo atributo de plantio ornamental a partir de modelos tipológicos herdados especialmente da cultura europeia.

Tal realidade começaria a modificar-se a partir dos anos 1930 na cidade carioca, que representa um marco de ruptura tanto para a prática quanto para o ensino da arquitetura paisagística, e traria progressivamente o interesse de arquitetos com a introdução da disciplina no curso de arquitetura e a definição e construção de um campo de atividade no Rio de Janeiro. Nesse pensamento admite-se que a institucionalização da disciplina de arquitetura paisagística não foi exclusivamente uma decisão pontual, e sim também favorecida por um processo histórico-social, resultante inclusive de um habitus construído ao longo de mais de um século na cidade.

Dessa forma construía-se um campo paisagístico na cidade do Rio de Janeiro propagado não só na arquitetura, como articulado à esfera política, econômica e social. Profícuo de ideais modernistas, a ele é também atrelada à iniciativa de Lucio Costa com a introdução da disciplina na ENBA. Em função de sua posição no campo, a atitude subversiva de Costa se caracteriza como a primeira institucionalização do ensino de arquitetura paisagística na cidade carioca e no Brasil, tornando-se pioneira nesse segmento em território nacional.

Todavia, o período de Lucio Costa à frente da ENBA é curto. Ele recebeu severas críticas do Conselho Técnico e Administrativo, que culminaram com sua destituição do posto de diretor da instituição. As resistências e campanhas movidas contra a sua administração levaram à sua demissão em 18 de setembro de 1931, não por acaso mês em que o 'Salão Revolucionário' abre as portas ao público. Nesse momento sua iniciativa renovadora foi apenas uma semente plantada, que posteriormente alimentou novos movimentos de oposição ao modelo de ensino da escola.

Depois da saída de Lucio Costa da ENBA, para ocupar a cadeira de Urbanismo e Arquitetura Paisagística foi nomeado interinamente em 18 de janeiro de 1932, pelo então Presidente da República, Getúlio Vargas, o arquiteto e urbanista Attílio Corrêa Lima. 


\section{ATTÍLIO CORRÊA LIMA, O PRIMEIRO PROFESSOR DE ARQUITETURA PAISAGISTA}

Attílio Corrêa Lima, segundo Ackel (2007), era filho do escultor José Octávio Corrêa Lima e da italiana Rosália Marzia Benfaremo, nascido em Roma no dia 8 de abril de 1901. Morou na Europa por cinco anos, quando veio para o Rio de Janeiro, lugar onde viveria a maior parte de sua vida. Cursou, como aluno livre, a ENBA, onde o pai era professor titular de Escultura e Ornatos. Após essa experiência inicial, em 1919 inscreveu-se no Curso Geral da ENBA, que concluiu em 1922. Deu continuidade a seus estudos iniciando o Curso Especial de Arquitetura em 1923.

Em 1927 foi contemplado com o prêmio "Viagem à Europa", e se estabeleceu em Paris, onde frequentou o Institut d'Urbanisme de L'Université de Paris (IUUP). Em sua permanência de cinco anos em Paris, estagiou no escritório de Alfred Agache durante a realização do seu plano para o Rio de Janeiro. Defendeu sua tese no ano de 1930 e retornou ao Brasil no final de 1931 como o primeiro urbanista formado do país.

Quando se graduou na ENBA, e antes de sua viagem a Paris, segundo Ackel (2007) participou de um concurso promovido pela Prefeitura do Distrito Federal. $O$ concurso consistia na escolha do projeto para o ajardinamento da Ponta do Calabouço, no qual obteve a segunda colocação. Segundo consta, nesse momento ele já gostava de paisagismo, porém não se dedicou a esses estudos no período em que esteve na França. Em contraponto, trouxe de lá, quando retornou, vários livros sobre o assunto.

Em entrevista realizada por Ackel com seu filho, Bruno Corrêa Lima, ele explica: "[...] meu pai gostava muito de paisagismo, mas ele era assim, uma espécie de autodidata. Ele sempre me levava para ver os jardins que estava fazendo e ficava me explicando o lugar de origem de cada planta" (LIMA, 2006 apud ACKEL, 2007, p. 231).

No acervo pessoal de Attílio Corrêa Lima, em pesquisa realizada por Ackel (2007), constam livros sobre paisagismo, jardinagem e botânica, além de um completo fichário onde catalogava todas as plantas usadas em seus projetos. Constam também cinco volumes de dicionários de Botânica, de autoria de Pio Corrêa. Tais constatações remetem à conclusão de que Corrêa Lima, entre outras coisas, se dispunha a estudar a flora nativa, e possivelmente fornecia esses conhecimentos nas aulas da ENBA, além de introduzi-las em seus projetos.

Recém-chegado ao país após sua pós-graduação em Urbanismo no Institut d'Urbanisme de L'Université de Paris (IUUP), sua indicação para catedrático da disciplina, conforme Ackel (2007), teve forte influência de seu pai, José Octávio Corrêa Lima, ex-diretor da ENBA por quatro anos antes da gestão de Lucio Costa. Em documento de 12 de abril de 1932, assinado por Getúlio Vargas e Gustavo Capanema, apresentado por Luiz Gonzaga Montans, diz-se:

O Presidente da República resolve nomear o professor ATTílIO CORRÊA LIMA para reger, interinamente, no corrente anno, até realização de concurso, a cadeira de Urbanismo-Architectura Paisagista do curso de Architectura da Escola Nacional de Bellas Artes, da Universidade do Brasil (ACKEL, 2007, p. 192). 
Attílio permaneceu interinamente nessa função até maio, quando foi designado por ato do Reitor, em 1 de junho de 1932, a reger a cadeira de Urbanismo e Arquitetura Paisagista, tornando-se o primeiro professor dessa disciplina na ENBA. Em certidão da ENBA, datada de 31/01/1935, diz-se:

Certifico que o docente livre deste estabelecimento, engenheiro-architecto Attílio Corrêa Lima, actualmente no exercício de professor de Urbanismo e Architectura Paisagística desde 1932, a contento da administração e com proveito para o ensino, vem lecionando a referida disciplina neste estabelecimento como contractado e interino, respectivamente. Certifico, outrossim, que o referido professor, durante o período que vem lecionando neste instituto, não só realizou excursões com os alunos da disciplina em apreço, como também tomou parte e serviu como examinador em várias bancas de exames e concursos de fim de anno (apud ACKEL, 2007, p. 191).

Corrêa Lima, segundo Ackel (2007), foi nomeado responsável pela cadeira de Urbanismo e Arquitetura Paisagista através de ato assinado em 14 de março de 1934, tendo permanecido como catedrático da disciplina até 1937. Todavia, em 1934 foi licenciado por precisar ausentar-se para a realização do Plano Urbanístico de Goiânia, onde necessitou residir. Neste ano o diretor da ENBA era o arquiteto Archimedes Memória, que em 14 de agosto concedeu a Attílio Corrêa Lima o título de Livre-Docente em arquitetura. Na mesma data o Ministro de Educação e Saúde, Gustavo Capanema, o designou como membro do Conselho Nacional de Belas Artes.

Segundo o Diário Oficial de 12 de fevereiro de 1935, no programa da cadeira de "Urbanismo e Architectura Paisagista" da ENBA, conforme o n 10 do Art. 6, do Decreto $n^{\circ} 22.897$, o conteúdo específico de arquitetura paisagística compreendia "[...] parques e jardins; o problema florestal; estudo summario das plantas como elementos de composição urbana" (DIÁRIO Oficial, 1935, p. 3186). Da mesma forma, ainda conforme o Diário Oficial, o programa para o concurso de docente da referida cátedra seria coberto por duas partes, e na especificidade da arquitetura paisagística era relacionado: 1) a arte dos jardins, destacando o estudo das duas grandes escolas, a francesa e a inglesa, juntamente com os jardins italianos e os jardins orientais; 2) técnica dos jardins, problema florestal, necessidade das "reservas de ar" nas cidades; 3) espécies vegetais utilizáveis no meio urbano - influências da temperatura, insolação, composição do terreno etc. sobre a vegetação; 4) arborização pública; 5) técnica e composição dos grandes parques, jardins públicos, jardins particulares e o problema do jardim mínimo.

É possível observar na constituição do programa disciplinar da arquitetura paisagística na ENBA interlocuções entre os saberes paisagísticos desse momento com o campo da botânica, das artes, da arquitetura e do urbanismo. Tal fato conduz à compreensão de que a profissão não era vista apenas pelo atributo de plantio ornamental ou aspectos formais. Apregoava-se a devida consciência técnica em seu labor.

Observa-se que o estudo do mundo vegetal em arquitetura paisagística estava mais próximo da botânica - campo da biologia que abrange ampla gama de disciplinas 
científicas dedicadas ao estudo do crescimento, reprodução, metabolismo, desenvolvimento, doenças e evolução da vida das plantas.

Nos programas referidos também se nota a preocupação com a conservação florestal. O papel da vegetação como "pulmão de ar" para as cidades foi uma reflexão muito presente nos estudos do urbanismo e do paisagismo desde meados do século XIX, tanto na Europa quanto nos Estados Unidos. É possível observar tal questão através dos conceitos que guiaram a criação de redes hierárquicas de espaços urbanos vegetados, como o Park System na Inglaterra; o plano de renovação urbana de Paris implementado por Jean-Charles Adolphe Alphand; a criação do Emerald Necklace, sistema linear de parques públicos implantado em Boston e a concepção do Central Park de Nova York, ambos nos Estados Unidos, por obra de Frederick Law Olmsted e Calvert Vaux.

No Brasil é possível observá-la através da prática de Auguste François-Marie Glaziou, a partir de 1860, e na preocupação com a recomposição da floresta da Tijuca. Porém, na atividade paisagística dessa fase, reflorestar significava o replantio de espécies, podendo estas serem exóticas ou nativas. $\bigcirc$ que determinava esse critério era $\circ$ acesso às sementes.

Diferentemente do século XIX, nesse momento o que se propunha na cidade do Rio de Janeiro era a conservação da própria floresta, onde ações antrópicas estavam relacionadas ao replantio quando necessário. É possível relacionar essa questão com o campo da Ecologia. Segundo Odum (2004), esta ciência estuda os seres vivos e suas interações com o meio ambiente onde vivem. No século XX, seu estudo emergiu das raízes nas ciências biológicas para tornar-se uma nova disciplina integrada, ligando as ciências naturais às sociais. Ampliando a compreensão de como os organismos interagem entre si e com o seu ambiente, os ecologistas alargaram a sua escala de estudo e o seu interesse com a inclusão de níveis mais altos de organização - o sistema ecológico, ou ecossistema, a paisagem, a região e a biosfera.

Havia, desde os anos 1920, a presença de um grupo de intelectuais e cientistas atuantes na proteção do meio ambiente brasileiro, em defesa da conservação dos recursos naturais e das diversidades florística e faunística do país, como descrevem Drummond e Franco (2009). Em 1934 realizou-se na cidade do Rio de Janeiro a 'Primeira Conferência Brasileira de Proteção à Natureza', na qual havia duas linhas argumentativas: em uma o mundo natural era valorizado como recurso econômico a ser usufruído racionalmente; na outra era objeto de culto e fruição estética. Nesta a ideia de paisagismo aparecia reforçando a perspectiva de uma "natureza jardim".

Compreende-se, dessa forma, a interseção entre o campo paisagístico desse momento: com a preocupação de proteger o meio ambiente e seu papel educativo na sociedade. Levar a vegetação para as cidades significava torná-la conhecida, sendo necessário priorizar as riquezas naturais do país a fim de promovê-las. Com isso seria possível sensibilizar os habitantes para a preservação e contribuir para 'forjar' a imagem da identidade nacional almejada pelo poder e a elite intelectual.

Contudo as manifestações culturais e as riquezas naturais não eram suficientes para fazer a população constituir-se politicamente. Era imperativa a prática de profissionais 
e fundamental a sua formação acadêmica. Para tanto era necessária a reforma da instituição herdada da Primeira República e do Império, que tentava atingir a modernidade através do regime academicista, baseado na referência do modelo francês, como é o caso da ENBA.

O caminho para o progresso significava 'dar forma à sociedade', e é nesse ponto que Lucio Costa atuou com a introdução das novas disciplinas. Nesse ínterim, Attílio Corrêa Lima ficou na docência da disciplina Urbanismo - Arquitetura Paisagista até o ano de 1937, quando em concurso público para professor efetivo foi preterido pelo engenheiro José Octacílio Saboya Ribeiro. Tal situação resultou em longo processo na justiça por irregularidades nos procedimentos do concurso, fato que o faz deixar a ENBA.

A partir de 1932, formaram-se no Curso Geral, sendo alunos de Attílio Corrêa Lima, consequentemente, arquitetos como Alcides da Rocha Miranda, Jorge Machado Moreira, Hélio Uchoa Cavalcanti, Jorge Ferreira, Carlos Frederico Ferreira. Estes, e muitos outros, colaboraram na formação de novas gerações de profissionais de grande relevância, mas que ainda aguardam por mais justo reconhecimento. Da mesma forma, um fato não pode ser modificado: Attílio Corrêa Lima não foi somente o primeiro professor de urbanismo da ENBA, ele foi o primeiro catedrático de arquitetura paisagística da cidade do Rio de Janeiro e do Brasil.

\section{CONSIDERAÇÕES FINAIS}

A cidade do Rio de Janeiro apresentava, no começo da década de 1930, um ambiente favorável à introdução do ensino de Arquitetura Paisagística. No âmbito histórico-social, havia um habitus instalado há mais de um século na valorização da prática paisagística, seja através da presença de espaços públicos vegetados - como o Passeio Público, construído em fins do século XVIII, o Jardim Botânico do Rio de Janeiro e o Campo de Santana, construídos no século XIX, as reformas paisagísticas do período Pereira Passos, efetuadas no começo do século XX -, seja por meio dos jardins privados que ornavam os palacetes, que configuraram a moradia da elite carioca desde os tempos da vinda da corte portuguesa nos primórdios do século XIX.

O habitus dos agentes, conforme Bourdieu (2011), inclina-os a conservar ou transformar as regras. Nesse sentido, o habitus do arquiteto Lucio Costa favoreceu sua atitude subversiva em sua reforma curricular, promovida na ENBA em 1931 e, consequentemente, a introdução, entre outras, da disciplina 'urbanismo e arquitetura paisagista'. Sua iniciativa tinha conexão com o ideário político-intelectual da época, caracterizado por preocupações nacionalistas e cientificistas, aliado ao desejo de modernização da sociedade e das instituições do estado.

Dessa forma, a iniciativa de Lucio Costa, iniciada nos anos 1930 e estendida até aproximadamente os anos 1970 - período que aqui será chamado de 'paisagismo modernista' -, estava atrelada à construção de um campo paisagístico. A institucionalização disciplinar pode ser considerada o marco da atividade de caráter modernista na 
cidade do Rio de Janeiro, caracterizada pela busca da identidade projetual da prática e sua própria configuração.

O campo do paisagismo modernista se distingue por embasar-se em conceitos de higienismo, pela formação de 'pulmões verdes' nas cidades e a educação da sociedade através da arte. Esses conceitos estavam presentes no ideário moderno do momento, e a própria insipiência da definição de atuação paisagística na cidade carioca e no Brasil levou os intelectuais nele atuantes a promover interlocuções com esferas mais amplas, como o debate político. Tal fato tornava o campo paisagístico, de certa forma, fluido e permeável, pela absorção de conceitos e teorias de outros saberes disciplinares, como a botânica, o urbanismo etc.

O habitus de Attílio Corrêa Lima também o guiou numa orientação modernista na disciplina de Urbanismo-Arquitetura Paisagista, como foi possível observar através do programa curricular. Seu aporte, de 1932 a 1937, até hoje não havia sido devidamente reconhecido. Apesar de haver estudos sobre a contribuição de Lucio Costa em sua passagem pela ENBA, ainda não se havia atentado para o fato de que esta foi a primeira institucionalização do ensino de arquitetura paisagista no país. Até então, julgava-se ter ocorrido por meio da colaboração do norte-americano Roberto Coelho Cardoso, na Universidade de São Paulo nos anos 1950, como expôs a arquiteta e pesquisadora Magnoli (2006).

As modificações promovidas no início dos anos 1930 na ENBA culminaram com a separação definitiva entre o curso de Arquitetura e o de Belas Artes. Com isso foi criada a Escola Nacional de Arquitetura, através da Lei n $n^{\circ}$ 452/37. Suas instalações, atualmente, continuaram na ENBA. Posteriormente, através do Decreto-Lei n 7.918/45, de 31 de Agosto de 1945, a Escola Nacional de Arquitetura passou a ser denominada Faculdade Nacional de Arquitetura (FNA).

Em 1961 a FNA passou a ocupar o atual endereço, na Cidade Universitária, Ilha do Fundão, e posteriormente recebeu a alcunha de Faculdade de Arquitetura e Urbanismo (FAU), integrante da atual Universidade Federal do Rio de Janeiro (UFRJ). A FNA, segundo o referido Decreto-Lei, ficou responsável pelos cursos de Arquitetura e de Urbanismo. A disciplina 'Urbanismo e Arquitetura Paisagista' permaneceu na grade curricular do curso, ministrada no $5^{\circ}$ ano, e durante algum tempo continuou sob os auspícios de José Otacílio Saboya Ribeiro. Só vieram a constituir duas disciplinas autônomas através de reforma curricular ocorrida nos anos 1970.

Por sua vez, em 1971 a ENBA passou a ser denominada Escola de Belas Artes (EBA), também vinculada à UFRJ. Em 1972 a EBA passou a oferecer o curso de Bacharelado em Composição Paisagística, que foi reconhecido pelo então Ministério de Educação e Cultura (MEC) em 1979. 


\section{REFERÊNCIAS BIBLIOGRÁFICAS}

ABREU, Maurício de A. Evolução urbana do Rio de Janeiro. 4 ed. Rio de Janeiro: IPP, 2013.

ACKEL, L. G. M. Attílio Côrrea Lima: uma trajetória para a modernidade. 2007. 342 f. Tese (Doutorado em Projeto de Arquitetura) - Faculdade de Arquitetura e Urbanismo, Universidade de São Paulo, São Paulo, 2007. doi: $10.11606 /$ T.16.2007.tde-17092010-164414

ACTA da Sessão da Congregação da Escola Nacional de Bellas Artes, realizada em 22 de Abril de 1931, sob a presidência do Sr. arquiteto Lucio Costa, Diretor, p. 194-196. Acervo do Museu D. João VI. Disponível em: <http:// www.docvirt.com/docreader.net/docreader.aspx? $b$ bib $=$ MuseuDJoaoVI\&pasta $=$ Encadernados\&pesq $=>$. Acesso em: 11 out. 2013.

AMARAL, A. A. Artes plásticas na Semana de 22. 5 ed. São Paulo: Editora 34, 1998.

BOURDIEU, P. Razões práticas: sobre a teoria da ação. 11 ed. São Paulo: Papirus, 2011.

BRASIL. Decreto n 14.343, de 7 de Setembro de 1920. Institui a Universidade do Rio de Janeiro. Diário Oficial [da] República Federativa do Brasil, Poder Executivo, Seção 1, Rio de Janeiro, DF, 10 de Setembro de 1920, p. 15115.

Decreto $n^{\circ}$ 19.850, de 11 de Abril de 1931. Cria o Conselho Nacional de Educação. Diário Official [da] República Federativa do Brasil, Poder Executivo, Rio de Janeiro, DF, 15 de Abril de 1931, p. 5799.

Decreto n 19.851, de 11 de Abril de 1931. Dispõe que o ensino superior no Brasil obedecerá, de preferência, ao sistema universitário, podendo ainda ser ministrado em institutos isolados, e que a organização técnica e administrativa das universidades é instituída no presente Decreto, regendo-se os institutos isolados pelos respectivos regulamentos, observados os dispositivos do seguinte Estatuto das Universidades Brasileiras. Diário Official [da] República Federativa do Brasil, Poder Executivo, Rio de Janeiro, DF, 15 de Abril de 1931, p. 5800.

. Decreto $n^{\circ} 19.852$, de 11 de Abril de 1931. Dispõe sobre a organização da Universidade do Rio de Janeiro. Diário Official [da] República Federativa do Brasil, Poder Executivo, Rio de Janeiro, DF, 4 de junho de 1931, p. 9219.

Decreto $n^{\circ} 22.897$, de 6 de julho de 1933. Altera disposições do Decreto n. 19.852, de 11 de abril de 1931, na parte referente à organização do ensino artístico ministrado pela Escola Nacional de Belas Artes, e dá outras providencias. Diário Oficial [da] República Federativa do Brasil, Poder Executivo, Rio de Janeiro, DF, 8 de jul. de 1933. Seção 1, p. 13532.

Decreto $n^{\circ} 22.897$, de 12 de Fevereiro de 1935. Programa da cadeira do curso de Architectura. Diário oficial [da] República Federativa do Brasil, Poder Executivo, Rio de Janeiro, DF, 12 de fev. de 1935, p. 3186 3187. Disponível em: <http://www.docvirt.com/docreader.net/docreader.aspx? bib=MuseuDJoaoVI\&pasta=\&pesq =urbanismo\%20architectura\%20paisagista $>$. Acesso em: 1 jul. 2016.

Lei 452, de 5 de julho de 1937. Organiza a Universidade do Brasil. Diário Oficial [da] República Federativa do Brasil, Poder Executivo, Rio de Janeiro, DF, 5 de jul. de 1937, p. 14830.

Decreto-Lei n 7.918, de 31 de Agosto de 1945. Dispõe sobre a organização da Faculdade Nacional de Arquitetura da Universidade do Brasil. Diário Oficial [da] República Federativa do Brasil, Poder Executivo. Rio de Janeiro, DF, Seção 1, 3 de ago. de 1945, p. 14409.

IV CONGRESSO Pan-Americano de Architectos. Jornal do Brasil, Rio de Janeiro, 2 jul. 1930, p. 8.

CONGRESSO Regionalista do Nordeste. O Paiz, Rio de Janeiro, 7 fev. 1926, p. 7.

DRUMMOND, J. A.; FRANCO, J. L. de A. Proteção à natureza e identidade nacional no Brasil, anos 1920 1940. Rio de Janeiro: Fiocruz, 2009.

LOS RIOS FILHO, A. M. Instituto Central de Architectos: posse da nova directoria. Revista de Architectura. Rio de Janeiro. Ano I, n 4 , Setembro 1929, p. 22-23.

. Regulamento do IV Congresso Pan-Americano de Architectos. Revista de Architectura. Rio de Janeiro. Ano $\overline{1, n^{\circ} 4}$, Setembro 1929, p. 26-27.

MAGNOLI, M. M. Paisagem: pesquisa sobre o desenho do espaço. Paisagem e Ambiente: ensaios. São Paulo: FAUUSP, n. 21, 2006, p. 223-236.

ODUM, E. P. Fundamentos de ecologia. 6 ed. Fundação Calouste Gulbenkian, 2004.

PARTIDO Economista do Brasil. Diário da Noite, Rio de Janeiro, 12 nov. 1932, p. 2.

PÉCAUT, Daniel. Os intelectuais e a política no Brasil: entre o povo e a nação. São Paulo: Ática, 1990.

PEREIRA, S. G. Arte brasileira no século XIX. Belo Horizonte: C/Arte, 2008. 
Alda de Azevedo Ferreira, Fernando Pedro de Carvalho Ono e Cláudia Carvalho Leme Nóbrega

PINHEIRO, M. L. B. Lucio Costa e a Escola Nacional de Belas Artes. In: SEMINÁRIO DOCOMOMO, 6, 2005, Niterói. Anais... Niterói: ArqUrb/UFF, 2005.

ROTHEN, J. C. A universidade brasileira na reforma Francisco Campos de 1931. Revista Brasileira de História da Educação. Maringá: SBHE, UEM, v. 8, n² 2, 2008, p. 140-160.

SAMPAIO, A. J. A flora do Rio de Janeiro, ao tempo da fundação. Correio da Manhã. Rio de Janeiro, 19 jan. 1930, p. 3.

Florística em architectura-paysagista. Correio da Manhã. Rio de Janeiro, 9 mar. 1930, p. 1.

ZANINI, W. Arte contemporânea. In: ZANINI, W. História geral da arte no Brasil. São Paulo: Instituto Moreira Salles, 1983, p. 499-820. 